See discussions, stats, and author profiles for this publication at: https://www.researchgate.net/publication/320273470

\title{
Solar powered smart irrigation system
}

Article in Journal of Engineering and Technology Management · July 2016

CITATION

1

2 authors, including:

(i)

Viswanatha v.

Acharya Institute of Technology Bangalore

10 PUBLICATIONS 8 CITATIONS

SEE PROFILE

Some of the authors of this publication are also working on these related projects:

Control of Bidirectional buck boost converter using Microcontrollers View project

Watering the field automatically based on the moisture level of the soil View project
READS

277 


\title{
Solar Powered Smart Irrigation System
}

\author{
Viswanatha V and Venkata Siva Reddy R \\ School of electrical and electronics Engineering, REVA University Bangalore, India \\ E-mail: vishwanathv@revainstitution.org /: vsreddy@revainstitution.org
}

\begin{abstract}
In the field of agriculture, use of proper method of irrigation is important because the main reason is the lack of rains and scarcity of land reservoir water. The continuous extraction of water from earth is reducing the water level due to which lot of land is coming slowly in the zones of un-irrigated land. Another very important reason of this is due to unplanned use of water due to which a significant amount of water goes waste. The system derives power from solar energy through photovoltaic cells. Hence, dependency on erratic commercial power is not required. In this paper we use solar energy which is used to operate the irrigation pump. The circuit comprises of sensor parts built using op-amp IC. Op-amp's are configured here as a comparator. Two stiff probes are inserted in the soil to sense whether the soil is wet or dry. A microcontroller is used to control the whole system by monitoring the sensors and when sensors sense dry condition of soil, then microcontroller will send command to relay driver IC the contacts of which are used to switch on the motor and it will switch off the motor when the soil is in wet condition. The microcontroller does the above job as it receives the signal from the sensors through the output of the comparator, and these signals operate which is stored in ROM of the microcontroller. The condition of the pump i.e., ON/OFF is displayed on a 16X2 LCD which is interfaced to the microcontroller. Further it can be enhanced in future by interfacing it with a GSM modem to gain control over the switching operation of the motor.
\end{abstract}

Keywords-Microcontroller;relays;sensors; solarpanel.

Asian Journal of Engineering and Technology Innovation

Volume 2016, Issue 3

Published on: 22/07/2016

Cite this article as: Viswanatha V and Venkata Siva Reddy R. Solar Powered Smart Irrigation System . Asian Journal of Enginnering Technology and Innovation, Vol 2016(3):1-2, 2016.

\section{INTRODUCTION}

In developing countries, most of available water is used for agriculture. With the increase in agricultural activity and competitive demand from different sectors, it became essential to economize on the use of water. This calls for optimal utilisation of available resources by adopting innovating methods of irrigation with scientific methods of scheduling. Agriculture in India has significant history. Most of the income in India is by exporting agricultural goods. Today, India ranks second world wide in farm output. Agriculture and allied sectors like forestry and fisheries accounted for $16.6 \%$ of the GDP in 2009 , about $50 \%$ of the total work force.

Energy of pumps used for the agricultural irrigation is generally provided from electrical energy or fossil fuels commence to annihilate besides its increasing prices and hazards to environment alternative energy seeking efforts has become inevitable also in agricultural sector. Solar energy that is sensitive to environment, clean and requiring no maintenance is an alternative renewable energy source especially for countries like Turkey having a high amount of annual solar irrigation rate. When it is considered by means of requirement for irrigation the advantage of PV pumping systems is that water demand and increasing sun shining.
In this process, solar energy is used to drive the pump-set. The circuit comprises of sensor parts built using op-amp IC. Op-amp's are configured here as a comparator. Two stiff probes are inserted in the soil to sense whether the soil is wet or dry.

A microcontroller is used to control the whole system by monitoring the sensors and when sensors sense dry soil then microcontroller will send command to relay driver IC the contacts of which are used to switch on the motor and it will switch off the motor when the soil is in wet condition.

\section{WORKING PRINCIPAL}

This project is broadly divided into two parts namely, Transmission and Receiving section. The transmission section is located in the field whereas the receiving section is located near the water source. The working starts from the transmission section which consists of moisture sensor, ADC, microcontroller and transmitter. The moisture sensor consists of two probes which are dipped into the soil, moisture content will be determined via its effect on dielectric constant by measuring the capacitance between two electrode implanted in 
the soil. Where soil moisture is predominantly in the form of free water, the dielectric constant is directly proportional to moisture content. The probe is normally given a frequency excitation to permit measurement of the dielectric constant. The moisture sensor detects the moisture content in the soil and generates an analog voltage signal, as this signal is weak it is amplified using OP-Amp LM343. This signal is fed to the ADC0804 which converts the analog signal into digital signal (because microcontroller works on digital signals only). Now the output of ADC is pulled up using pull up transistors and interfaced with PORT-1 of the microcontroller. The microcontroller is programmed in such a way that the input (from ADC) at PORT-1 is monitored using LED's connected at PORT-2.

The microcontroller starts processing the signal by comparing the input signal with the preset (reference) value. When the analog signal from moisture sensor falls below the preset value then the microcontroller determines the water content is less in the soil and triggers the transmitter module which is connected to PORT-3.7 by sending a pulse using pull up transistor. The transmitter operates at the frequency of $434 \mathrm{MHz}$, thus sends the wireless signal to the receiver module at receiving section located near the water source.

As we know different crops require different amount of water for their proper cultivation, therefore solving this problem becomes inevitable. Thus the control switches are implemented. By controlling these switches the microcontroller compares the input signal with their respective preset value meant for different amount of water for crops and sends the signal to the transmitter module.

A).Transmitter: The signal sent by the transmitter is received by receiving section, consists of $\mathrm{RF}$ receiver module, microcontroller 89V51RD2 (2No's), LCD (2No's), motor driver L293D, Relay and water pump. The signal is received by the receiver which is connected to the P1.0 of the $1^{\text {st }}$ microcontroller. Depending upon the input signal the microcontroller controls the operation of the pump, using the motor driver and the relay. To switch on the pump microcontroller gives the signal to the motor driver IC which is connected to the $12 \mathrm{~V}$ source (battery). To make the project more flexible we are using a relay so that we can use high rating motors to drive the pump. Here the tripping signal to the relay is being sent by the motor driver itself. The condition of the pump can be monitored on the first LCD.

The complete transmitter circuit is as shown in Fig. 1 The power source for the pump is a battery which is being charged from solar panel. A solar charge controller is used in between solar panel and battery to regulate the voltage required for charging the battery.

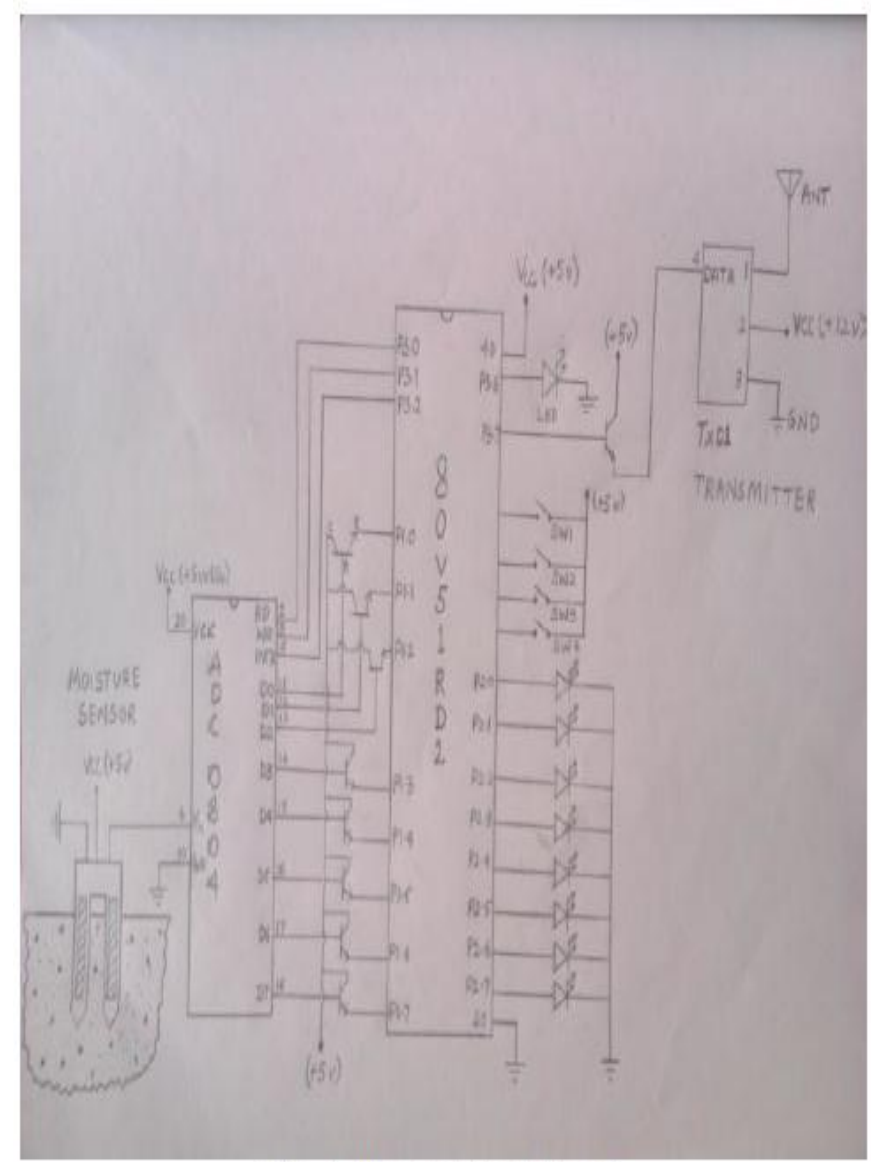

Fig. 1. Transmission Circuit

B). Receiver : Receiving section also consists of a clock circuit, which continuously runs the clock which is monitored on the second LCD. The $2^{\text {nd }}$ microcontroller is programmed to run the clock continuously and imultaneously monitoring the peak hours i.e. $11 \mathrm{AM}$ to $4 \mathrm{PM}$ during which the sun is at the peak and the temperature will be high.The complete receiver circuit is as shown in Fig. 2. From the survey it is confirmed that the plant should not be irrigated during peak hours, as the plants warm and may get harmed. The $2^{\text {nd }}$ microcontroller is programmed in such that it halts the operation of the receiving section during $11 \mathrm{AM}$ to $4 \mathrm{PM}$ irrespective of the signal it gets from transmission section. 


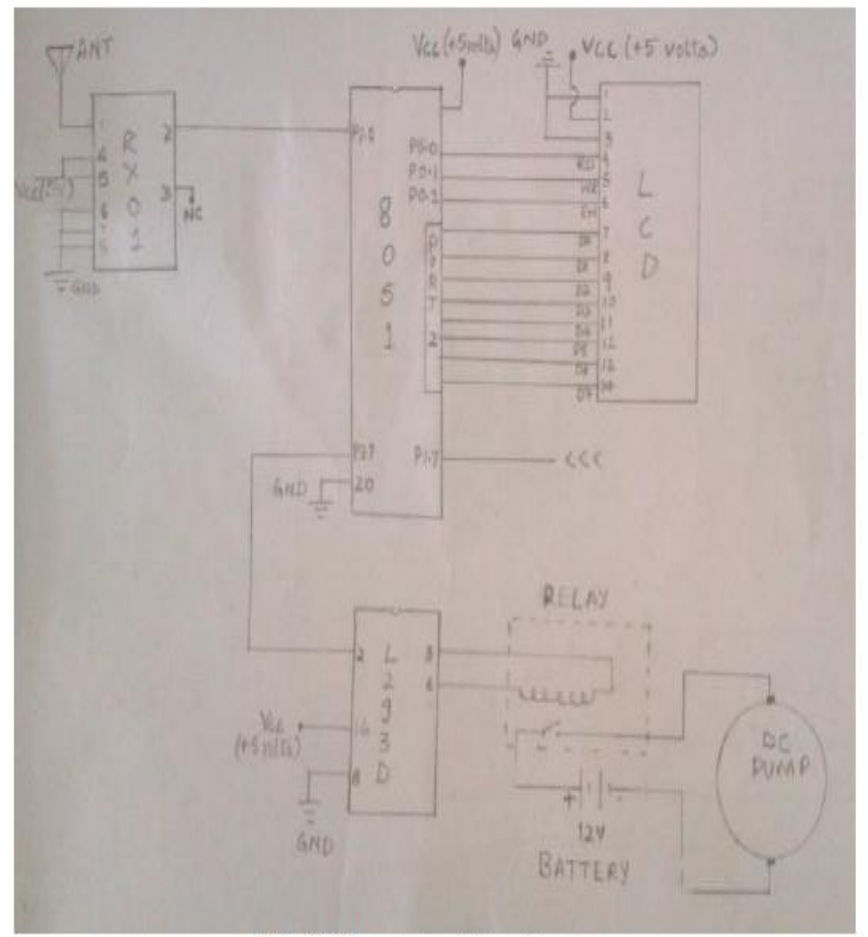

Fig. 2. Receiving Circuit

C). Clock Circuit: Clock circuit is as shown in Fig. 3 which shows how power is supplied from solar panel to microcontroller as well as to water pump.

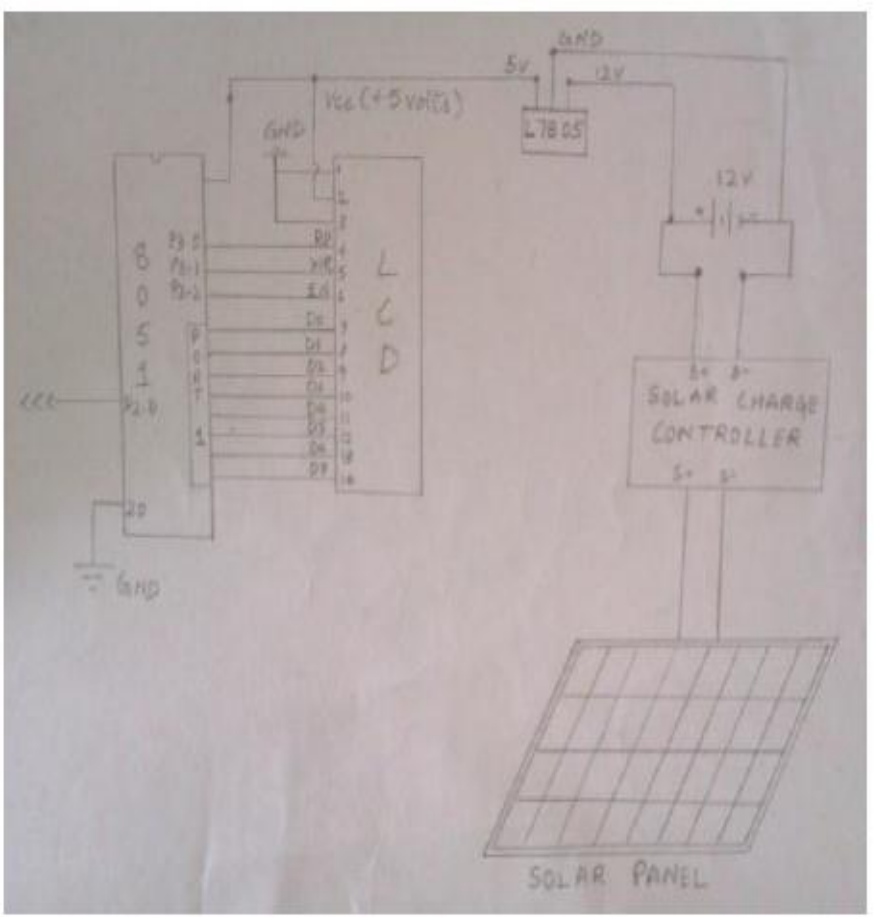

Fig. 3. Clock Circuit

\section{TECHNICAL SPECIFICATION}

TABLE. 1. TECHNICAL SPECIFICATION

\begin{tabular}{|c|c|}
\hline COMPONENTS & RATING \\
\hline MOISTURE SENSOR & $\begin{array}{l}\text { Input Voltage- } 5 \mathrm{~V} \text { Dc \& } \\
\text { Rated Voltage }(0.6-5 \text { volts })\end{array}$ \\
\hline $\mathrm{ADC}$ & 0804, 20 PINS \\
\hline SOLAR CHARGE CONTROLLER & $\begin{array}{l}\text { Input voltage-20V Dc and } \\
\text { Output Voltage-12V Dc }\end{array}$ \\
\hline MICROCONTROLLER & 89V51RD2, 40 PINS \\
\hline RF MODULE & $\begin{array}{l}\text { Input Voltage-5volt \& } \\
\text { operating frequency- } \\
\text { 315/433.92MHZ }\end{array}$ \\
\hline DC MOTOR & $\begin{array}{l}\text { MODEL- RTP27D02R } \\
\text { Voltage- 12V DC } \\
\text { Current- } 280 \mathrm{~mA}\end{array}$ \\
\hline PV MODULE & $\begin{array}{l}\text { Output Voltage- } 20 \mathrm{~V} \& \\
\text { Power- } 7.5 \text { watt }\end{array}$ \\
\hline BATTERY & $\begin{array}{l}\text { Rated Voltage- } 12 \mathrm{~V} \& \\
\text { Rated Current- 5A }\end{array}$ \\
\hline
\end{tabular}

\section{HARDWARE IMPLEMENTATION}

The Fig. 4 is input module, Fig. 5 is output module, Fig. 6 clock circuit and charger, Fig. 7 complete circuitry which are all implemented on hardware of the irrigation system. 


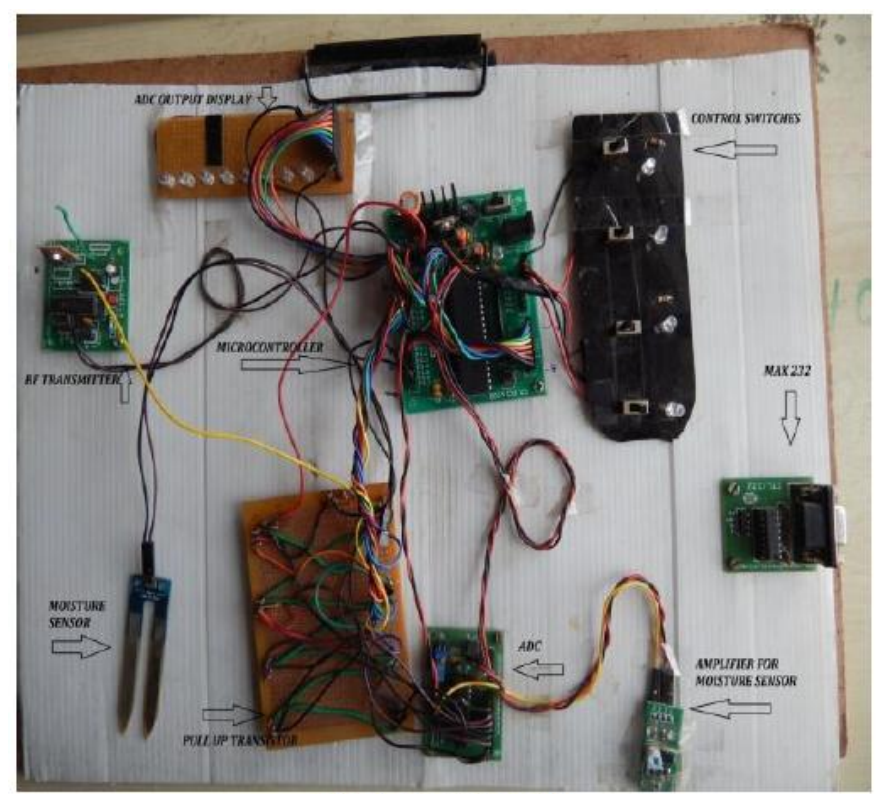

Fig .4. Input module.
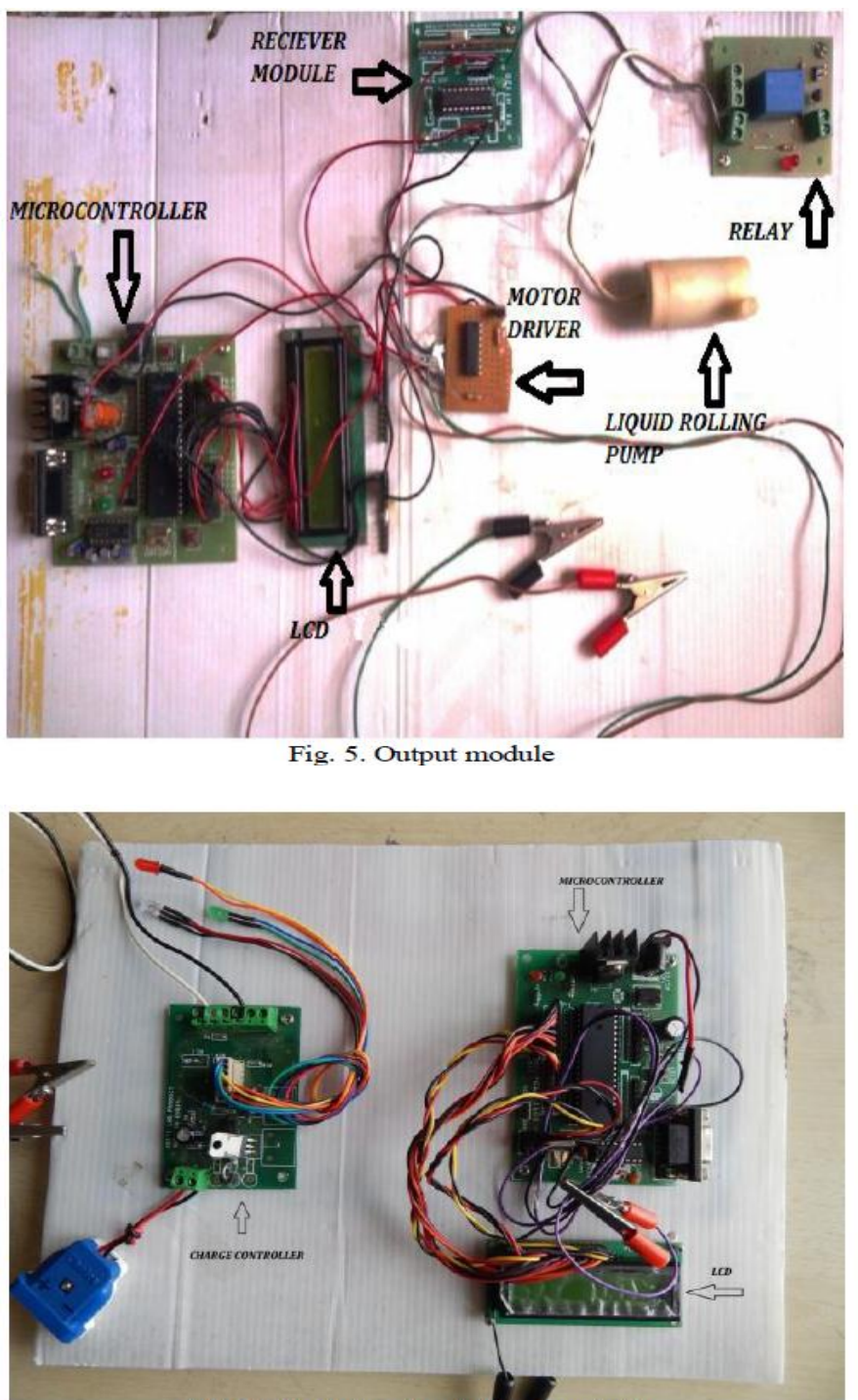

Fig. 6. Clock circuit and charge controller

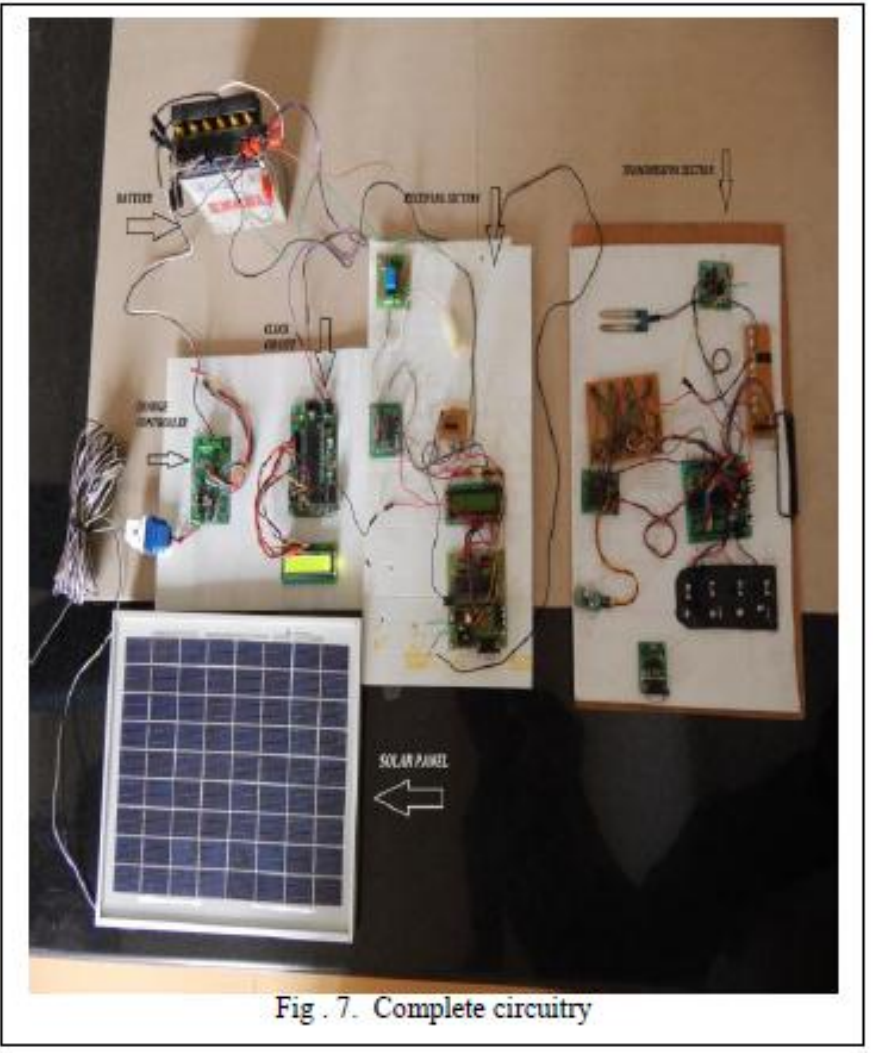

\section{ADVANTAGES AND DISADVANTAGES}

In this section advantages and disadvantages of this solar based water irrigation system of implementation is described as follows

\section{A). ADVANTAGES}

- Water Management

A Solar Powered Based Irrigation System provides efficient usage of the water with precise delivery of the required volumes of water through high pressure misting for the seedlings or lower pressure drip irrigation for more mature plants.

- Labour

Solar Powered Automated Irrigation System provides consistency in watering pattern week over week. No overtime cost associated with weekend employment of labour are incurred, since the system is programmable, promoting scientific application of soil and plant additives.

- Flexibility

Since the system is programmable it is flexible for different types of crops by using different types of switches under different climatic condition and area.

\section{- Energy}

Perhaps the most profound impact of the solar powered automated system is in this area where the sun's energy is used to power the complete system. This is achieved by 
Photovoltaic Panels to convert the sun's energy to DC current to drive pump, valves, timer, and to charge the battery.

- Sustainability

Solar Powered irrigation provides a cleaner source of energy that is less susceptible to global price fluctuations.

\section{B). DISADVANTAGES}

\section{Climatic Conditions}

- During bad climatic condition the electricity generated is not efficient and hence the battery is not charged properly due to which the Power required for the system to run is insufficient.

- Cost Parameters

The initial cost for the system if applied in small scale is large but the capital invested can be regained in no time if applied for large scale.

- Soil Moisture Sensors

\section{CONCLUSION}

In this paper, a wireless data acquisition network implemented and applied to irrigate different agricultural field. The developed irrigation automation system can be proposed to be used in several commercial agricultural productions since it was obtained in low cost and in reliable operation. This application of sensor based site specific has some advantages such preventing moisture stress of trees, diminishing of excessive water usage, ensuring of rapid growing weeds and derogating calcification.

If different kinds of sensors (that is, temperature, humidity, etc) are involved in such irrigation in future works, it can be said that an internet based remote control of irrigation automation will be possible. The developed system can be transfer fertilizers and the other agricultural chemicals (calcium, sodium, ammonium, zinc) to the field with adding new sensor and valves.

\section{REFERENCES}

[1] Van Dyk, E. E. A. R. Gxasheka, and E. L. Meyer, 2005. Monitoring current voltage characteristics and energy output of silicon photovoltaic modules. Renewable sources of Energy. 30:399-411

[2] Van Dyk, E.E.,E.L. Meyer, F. J. Vorster, and A. W. R. Letich. 2002 Long term monitoring of photovoltaic devices. Renewable energy Sources. 25:183-197
[3] Vilela, O. C., N. Fraidenraich, and C. Tiba 2003. Photovoltaic pumping system driven by tracking collectors : experiments and simulation. Solar Energy. 74:45-52

[4] Muhammad Ali Mazidi: The 8051 Microcontroller $2^{\text {nd }}$ edition 